\title{
Vigor e viabilidade em aquênios de girassol determinados pelo teste de tetrazólio
}

\author{
Vigor and viability sunflower achenes as determined \\ by the tetrazolium test
}

'Departamento de Fitotecnia, Universidade Federal de Viçosa (UFV), Av. P. H. Ralfs, s/n, Centro, CEP 36571-000, Viçosa, MG, Brasil 2Laboratôrio de Análises de Sementes, Instituto de Ciências Agrărias (ICA), Universidade Federal de Minas Gerais (UFMG), Montes Claros, MG, Brasil Departamento de Melhoramento de Plantas, Universidade Federal Rural de Pernambuco (UFRPE), Recife, PE, Brasil

* autor correspondente 凶danubia_nobre@yahoo.com.br
RESUMO: Objetivou-se com o presente estudo avaliar aquênios de genótipos de girassol por meio do teste de tetrazólio. Utilizaram-se dezenove genótipos. O teor de água foi determinado pelo método padrão da estufa $\left(105 \pm 3{ }^{\circ} \mathrm{C}\right.$ durante 24 horas). Para o teste de tetrazólio, os aquênios foram submetidos ao pré-condicionamento para a remoção do tegumento, em seguida, os embriões foram imersos na solução de tetrazólio a $1 \%$ e, avaliados por meio de cinco classes. As médias foram comparadas pelo teste Tukey a $5 \%$. O teste de tetrazólio é eficiente na determinação da viabilidade e vigor dos genótipos de girassol, por meio do mesmo, os genótipos CF 101, Helio 358 e SY 3840 mostraram menor qualidade de sementes.

PALAVRAS-CHAVE: Helianthus annuus L., teor de água, tetrazólio.
ABSTRACT: The objective of the present study was to evaluate achenes of sunflower genotypes through tetrazolium test. Nineteen genotypes were used. The water content was determined by standard oven method (105 $\pm 3{ }^{\circ} \mathrm{C}$ for 24 hours). For the tetrazolium test, the seeds were subjected to preconditioning for the removal of the seed coat, then the embryos were immersed in tetrazolium solution $1 \%$ and analyzed through five classes. Means were compared by Tukey test at 5\%. The tetrazolium test is effective in determining the viability and vigor of sunflower genotypes through the same, the CF 101, 358 and Helio SY 3840 genotypes showed poorer quality seed.

KEYWORDS: Helianthus annuus L., water content, tetrazolium.

O girassol (Helianthus annuus L.) é uma cultura que apresenta características agronômicas importantes, tais como tolerância a seca, ao frio e ao calor, desenvolvendo-se bem em diferentes climas. Suas sementes podem ser utilizadas para alimentação animal ou para extração de óleo, que apresenta alta qualidade para o consumo humano ou pode ser utilizado como matéria prima na produção de biodiesel (LEITE; BRIGHENTI; CASTRO, 2005).

A produção de girassol no Brasil tem tido incrementos significativos, com uma produção de 208,2 mil toneladas (COMPANHA..., 2014). Diante do crescimento da cultura, é preciso considerar formas de maior rendimento e para isto é importante que se tenha sementes de boa qualidade, que apresentem elevada viabilidade e vigor.

O teste de tetrazólio pode determinar rapidamente a viabilidade das sementes (BRASIL, 2009; SILVA et al., 
2013). Entre outras aplicações está a avaliação do vigor, dos danos por secagem, por insetos e por umidade e também a detecção de danos mecânicos ocorridos durante a colheita e/ ou beneficiamento (BRASIL, 2009).

Há diversas condições que podem interferir nos resultados obtidos pelo teste padrão de germinação, porém, estas não afetam o teste de tetrazólio, que é realizado com equipamentos baratos e simples (KRZYZANOWSKI; VIEIRA; FRANÇANETO, 1999). O teste é baseado na atividade das enzimas desidrogenases no processo de respiração dos tecidos das sementes. Durante a respiração, os íons de hidrogênio reagem com o sal cloreto 2,3,5 trifenil de tetrazólio, resultando na coloração avermelhada nos tecidos vivos da semente (DELOUCHE et al., 1976).

Diante do exposto, o teste de tetrazólio é recomendado para fornecer uma rápida determinação da qualidade fisiológica das sementes e apresenta grande importância na tomada de decisão para o armazenamento e à comercialização das mesmas. Com base nestas informações, objetivou-se avaliar o vigor e a viabilidade em aquênios de genótipos de girassol.

As sementes foram cultivadas em blocos casualizados com quatro repetições, totalizando 40 parcelas experimentais de $16,8 \mathrm{~m}^{2}$ cada e, as plantas espaçadas em $0,70 \mathrm{~m}$. A semeadura foi realizada no período de safrinha, do ano agrícola de 2011, na Fazenda Experimental da Empresa de Pesquisa Agropecuária de Minas Gerais (Epamig), no município de Nova Porteirinha, situado ao norte do estado de Minas Gerais.

Ao final do ciclo de produção, quando os capítulos encontravam-se no ponto de maturidade fisiológica, as sementes dos diferentes genótipos de girassol: BRS G29, BRS G30, BRS G32, BRS G33, CF 101, GNZ CIRO, HLA 11-26, HLA 44-49, HLA 06270, Helio 358, M 734, QC 6730, Sulfossol, SYN 034A, SYN 039A, SY 3840, SY 4065, V 70004 e V 70153, foram colhidas e encaminhadas ao Laboratório de Análise de Sementes do Instituto de Ciências Agrárias da Universidade Federal de Minas Gerais, na cidade de Montes Claros - MG.
As sementes (fruto seco tipo aquênio) foram previamente selecionadas, manualmente, separando-se as mal formadas ou chochas, das sementes puras.

O teor de água dos aquênios foi determinado conforme Brasil (2009), utilizando o método padrão da estufa, a $105 \pm 3{ }^{\circ} \mathrm{C}$, durante 24 horas, com três repetições de 15 gramas de sementes para cada genótipo em estudo, sendo os resultados expressos em porcentagem de teor de água.

O teste de germinação realizado previamente, conforme as recomendações das regras de análises de sementes (BRASIL, 2009), apresentou médias iguais ou superiores a $80 \%$ de germinação para os genótipos: BRS G29, Sulfossol, V 70004, BRS G29, BRS G30, CF 101, GNZ CIRO, Hélio 358, HLA 44-49, SYN 039A, QC 6730 e V70153.

O teste de tetrazólio foi realizado conforme uma das metodologias prescritas pelas Regras para Análise de Sementes (BRASIL, 2009). Os aquênios dos diferentes genótipos de girassol foram submetidos ao pré-condicionamento para a remoção do tegumento, por meio da imersão direta em $200 \mathrm{~mL}$ de água, por 18 horas em câmara BOD, a $20{ }^{\circ} \mathrm{C}$. Em seguida, removeram-se o pericarpo das sementes e a membrana fina (endosperma), que envolve o embrião. Logo após, os embriões foram imersos na solução de cloreto 2,3,5 trifenil tetrazólio a $1,0 \%$ e mantidas no escuro em câmara B.O.D. a $30^{\circ} \mathrm{C}$ por 3 horas para coloração. Na sequência, os embriões foram lavados em água corrente e analisados individualmente (BRASIL, 2009).

Apenas as células vivas são coloridas no teste de tetrazólio, portanto, a diferenciação de cores dos tecidos na parte externa das sementes foi observada, por meio das cinco classes de viabilidade e vigor, determinadas pelo teste, de acordo com os critérios estabelecidos por Bhering, Dias e Barros (2005), para sementes de melancia e, adaptados no presente estudo para a cultura do girassol (Figura 1).

Classe 1: Sementes viáveis de alto vigor, com aspecto normal e firme, coloração uniforme rosa brilhante a vermelho carmim não muito intenso na superfície externa do embrião.
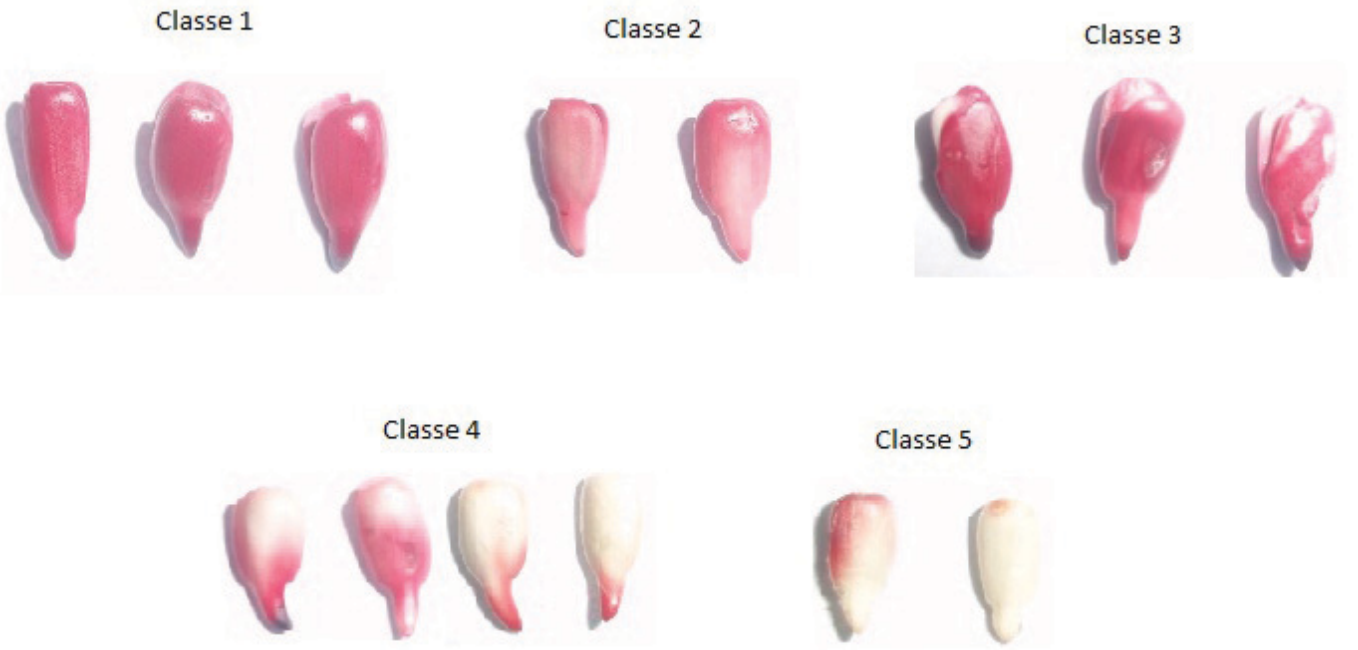

Figura 1. Classes para a determinação da viabilidade e do vigor de sementes de girassol. 
Classe 2: Sementes viáveis de médio vigor: apresentam coloração externa rosa claro a vermelho carmim mais forte e já aparecem pequenas manchas com profundidade inferior a 0,5 mm em áreas não críticas dos cotilédones, ocupando menos de $1 / 3$ da área dos mesmos. As manchas podem ter aspecto de mosaico (bordas vermelho intenso e centro branco leitoso).

Classe 3: Sementes viáveis não vigorosas: coloração rosa claro ou vermelho, apresentando manchas vermelho intenso com profundidade superior a $0,5 \mathrm{~mm}$ nos cotilédones. As manchas podem se apresentar com aspecto de mosaico, não devendo atingir mais de $50 \%$ da área dos cotilédones, nem a região de ligação desses com o eixo embrionário.

Classe 4: Sementes não viáveis: ambos os cotilédones com a metade superior branco leitoso. Manchas de um vermelho intenso mescladas de branco leitoso, ocupando mais de 50\% da área total dos cotilédones. Eixo embrionário apresentando mais de 50\% da área descolorida (branco leitoso), indicando tecido morto.

Classe 5: Sementes mortas: ambos os cotilédones com tecido totalmente vermelho intenso ou com áreas de coloração branco leitoso em mais de $50 \%$ da sua extensão. Eixo embrionário completamente branco leitoso, independente do estado dos cotilédones. Embrião com coloração branco leitoso em toda a sua extensão.

O potencial de vigor foi obtido pelo somatório do número de sementes das classes 1 e 2 , e a viabilidade pela soma do número de sementes das classes 1 a 3 . Os resultados foram submetidos à análise de variância e as médias foram comparadas pelo teste Tukey, em nível de 5\% de probabilidade.

Os resultados do teor de água referente aos aquênios de girassol apresentaram valores médios entre 4,2 a 5,3\%. Conforme Coimbra et al. (2007), o teor de água inicial das sementes é um fator primordial para a padronização dos testes de avaliação de qualidade, pois, o elevado teor de água das sementes pode favorecer o desempenho das mesmas nos testes. Já, Christensen (1969) relatou que o teor de água das sementes abaixo do limite máximo de 10,0\%, é o considerado ideal para o armazenamento das mesmas. Portanto, os resultados obtidos para o teor de água dos diferentes genótipos de girassol, não interferiram na avaliação da viabilidade.

Outro fator de grande importância é a qualidade do embrião, pois, este é responsável pela formação da nova planta. Para as sementes de girassol, a área vital inclui todo o embrião (eixo embrionário e endosperma). As sementes foram avaliadas, quantificadas e classificadas pelo teste de tetrazólio, de acordo com a diferenciação de cores dos tecidos da parte externa (Figura 1).

A coloração dos tecidos foi favorecida pela remoção do tegumento dos aquênios após a imersão direta das sementes em água. O mesmo foi comprovado por Grzybowski et al. (2012), em estudo com cevada, para a condução do teste de tetrazólio.

$\mathrm{Na}$ Tabela 1, encontram-se os resultados do teste de tetrazólio para as diferentes classes. Os resultados exibiram diferenças $(\mathrm{P} \leq 0,05)$ para os distintos genótipos nas classes

Tabela 1. Resultados médios obtidos por meio do teste de tetrazólio e suas classes (Classe 1: sementes viáveis de alto vigor; Classe 2: sementes viáveis de médio vigor; Classe 3: sementes viáveis não vigorosas; Classe 4: Sementes não viáveis e Classe 5: sementes mortas) para os diferentes aquênios de girassol.

\begin{tabular}{|c|c|c|c|c|c|}
\hline \multirow{2}{*}{ Genótipos } & \multicolumn{5}{|c|}{ Classes } \\
\hline & C 1 & C 2 & C 3 & C 4 & C 5 \\
\hline BRS G29 & $73 \mathrm{a}$ & $17 \mathrm{abc}$ & 6 cdefg & $3 \mathrm{~g}$ & $0 \mathrm{c}$ \\
\hline BRS G30 & 32 efg & $26 \mathrm{a}$ & $0 \mathrm{~g}$ & $39 \mathrm{bc}$ & $0 \mathrm{c}$ \\
\hline BRS G32 & $57 \mathrm{bc}$ & $8 \mathrm{~cd}$ & 4 defg & $30 \mathrm{bcd}$ & $1 \mathrm{c}$ \\
\hline BRS G33 & 47 cde & $11 \mathrm{bcd}$ & 2 efg & $35 \mathrm{bcd}$ & $0 \mathrm{c}$ \\
\hline CF 101 & $12 \mathrm{~h}$ & $17 \mathrm{abc}$ & $18 \mathrm{a}$ & $40 \mathrm{bc}$ & $13 \mathrm{ab}$ \\
\hline GNZ CIRO & 45 cde & $19 a b$ & $15 a b$ & $15 \mathrm{efg}$ & $6 a b c$ \\
\hline HÉLIO 358 & $21 \mathrm{fgh}$ & $18 a b c$ & $18 \mathrm{a}$ & $33 \mathrm{bcd}$ & $8 a b c$ \\
\hline HLA 06270 & 43 cde & $13 \mathrm{bcd}$ & $0 \mathrm{~g}$ & $43 \mathrm{ab}$ & $0 \mathrm{c}$ \\
\hline HLA 11-26 & 44 cde & $12 \mathrm{bcd}$ & 8 bcdef & $21 \mathrm{def}$ & $14 \mathrm{a}$ \\
\hline HLA 44-49 & $38 \mathrm{de}$ & $19 \mathrm{ab}$ & 6 cdefg & 28 cde & $8 a b c$ \\
\hline M 734 & $52 \mathrm{~cd}$ & $12 \mathrm{bcd}$ & $0 \mathrm{~g}$ & $36 \mathrm{bc}$ & $0 \mathrm{c}$ \\
\hline QC 6730 & $37 \mathrm{de}$ & $15 \mathrm{bc}$ & $13 a b c$ & 26 cde & $8 a b c$ \\
\hline SULFOSSOL & $72 \mathrm{ab}$ & $12 \mathrm{bcd}$ & 9 bcde & $2 \mathrm{~g}$ & $4 \mathrm{bc}$ \\
\hline SY 3840 & $17 \mathrm{gh}$ & $13 \mathrm{bcd}$ & $10 \mathrm{bcd}$ & $46 \mathrm{ab}$ & $13 \mathrm{a}$ \\
\hline SY 4065 & 44 cde & $13 \mathrm{bcd}$ & 4 defg & $36 \mathrm{bc}$ & $0 \mathrm{c}$ \\
\hline SYN 034A & 42 cde & $3 \mathrm{~d}$ & 6 cdefg & $40 \mathrm{bc}$ & $0 \mathrm{c}$ \\
\hline SYN 039A & $35 \mathrm{ef}$ & $26 \mathrm{a}$ & 4 defg & $33 \mathrm{bcd}$ & $0 \mathrm{c}$ \\
\hline V 70004 & $76 \mathrm{a}$ & $14 \mathrm{bc}$ & $1 \mathrm{fg}$ & $7 \mathrm{fg}$ & $0 \mathrm{c}$ \\
\hline V70153 & $56 \mathrm{c}$ & $12 \mathrm{bcd}$ & $0 \mathrm{~g}$ & $30 \mathrm{bcd}$ & $1 \mathrm{c}$ \\
\hline
\end{tabular}

Médias seguidas de mesma letra nas colunas não diferem entre si pelo teste de Tukey a 5\%. 


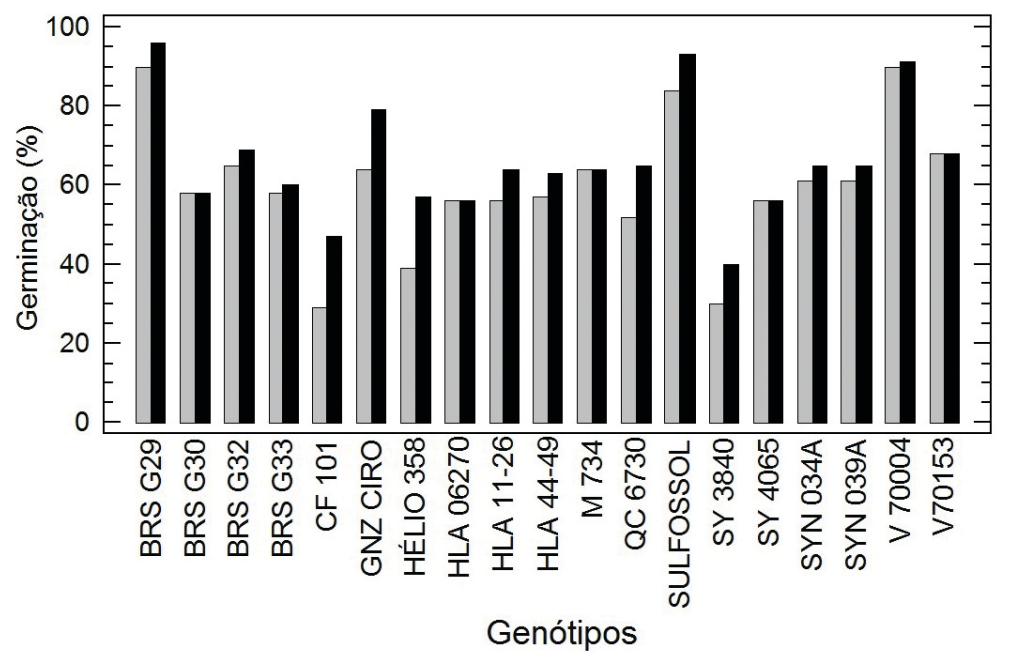

$\mathrm{TZ}(1-2) \% \square \mathrm{TZ}(1-3) \%$

Figura 2. Estimativa do vigor, classes de sementes (TZ 1-2: sementes viáveis de alto vigor e viáveis de médio vigor) e viabilidade (TZ 1-3: sementes viáveis de alto vigor; viáveis de médio vigor e viáveis não vigorosas), obtida por meio do teste de tetrazólio em aquênios de genótipos de girassol.

avaliadas, confirmando, portanto, o bom potencial de qualidade de alguns materiais estudados.

De acordo com as descrições das classes para o teste de tetrazólio (Figura 1, Tabela 1), para a classe 1, que apresenta as sementes viáveis e de alto vigor, nota-se entre os genótipos maiores médias para BRS G29, Sulfossol, V 70004. Para a classe 2 , sementes viáveis de médio vigor, o destaque foi expresso pelos genótipos BRS G29, BRS G30, CF 101, GNZ CIRO, Hélio 358, HLA 44-49 e SYN 039A. Já a classe 3, sementes viáveis não vigorosas, tem-se os genótipos: $\mathrm{CF}$ 101, GNZ CIRO, Hélio 358, QC 6730 como aqueles que apresentaram as maiores médias; enquanto que, para a classe 4, de sementes não viáveis, os genótipos HLA 06270 e SY 3840, apresentaram as maiores médias. Por fim, a classe 5, denominada pelas sementes mortas, apresentou um maior número dessas, para os genótipos: CF 101, GNZ CIRO, HÉLIO 358, HLA 11-26, HLA 44-49, QC 6730, SY 3840.

Para facilitar a classificação dos aquênios de girassol, por meio do teste de tetrazólio, o vigor e a viabilidade das sementes, foram respectivamente, denominados em duas classes, sendo, as classes 1-2 (sementes viáveis de alto vigor e viáveis de médio vigor) e 1-3 (sementes viáveis de alto vigor; viáveis de médio vigor e viáveis não vigorosas), conforme expresso na Figura 2. Assim, exibiram os genótipos CF 101, Helio 358 e SY 3840, como os de menor qualidade por meio do teste de tetrazólio. Estes genótipos apresentaram-se ainda, como os de maiores porcentagens para as classes $\mathrm{C} 4$ e C5, que são caracterizadas como sementes não viáveis e sementes mortas, respectivamente (Tabela 1).

O teste de tetrazólio pode contribuir, sobremaneira, com a diferenciação da qualidade de lotes de sementes, com a vantagem de ser executado com maior rapidez e precisão (ASSOCIATION..., 1983; FRANÇA-NETO; KRZYZANOWSKI; COSTA, 1999). No presente estudo, nota-se a diferença na qualidade das sementes dos diferentes genótipos por meio do teste, conforme apresentado na Tabela 1 e 2, resultados similares foram observados em estudo realizado por Silva et al. (2013) ao avaliarem aquênios de girassol.

Visto que, se trata de um teste rápido e confiável na análise de sementes, fornecendo mais rapidamente informações que o teste padrão de germinação, o teste de tetrazólio é recomendado para a avaliação de várias espécies, como sementes de milho (Zea mays L.), forrageiras (Brachiaria brizantha), oleaginosas (Glycine max (L.) Merrill) e espécies florestais (Xylopia aromatica) entre outras (CHAMMA; NOVEMBRE, 2007; CARVALHO et al., 2012; SOCOLOWSKI; CICERO; VIEIRA, 2012).

Diante do exposto, a utilização das classes enumeradas de 1 a 5, relatadas por Bhering, Dias e Barros (2005), em sementes de melancia, e adaptada para aquênios de girassol no presente estudo, possibilita distinguir o vigor e viabilidade das sementes dos diferentes genótipos, não havendo inferência na qualidade da avaliação. O mesmo foi observado por Silva et al. (2013), ao avaliar o vigor das sementes de girassol, com a emergência de plântulas, o que conferiu confiabilidade para a classificação dos lotes.

No presente estudo, o teste padrão de germinação foi o que comprovou a confiabilidade do teste tetrazólio, uma vez que, os genótipos que apresentaram valores $\geq 80 \%$ de germinação, foram aqueles mesmos, que exibiram as maiores médias de viabilidade e vigor, exceto, para o V70153, que não encontra-se nas classes 1-2 e 1-3. Logo, o teste de tetrazólio, contribuiu de maneira significativa para apresentar a elevada qualidade de alguns genótipos.

\section{Conclusões}

Conclui-se com o presente estudo, que o teste de tetrazólio é eficiente na determinação da viabilidade e do vigor das sementes dos genótipos avaliados, sendo as sementes dos genótipos CF 101, Helio 358 e SY 3840 as de menor qualidade. 


\section{Referências}

ASSOCIATION OF OFFICIAL SEED ANALYSTS - AOSA. Seed vigor testing handbook. East Lansing, 1983.93 p. (Contribution, $32)$.

BHERING, M. C.; DIAS, D. C. F. S.; BARROS, D. I. Adequação da metodologia do teste de tetrazólio para avaliação da qualidade fisiológica de sementes de melancia. Revista Brasileira de Sementes, Pelotas, v. 27, n. 1, p. 176-182, 2005.

BRASIL. Ministério da Agricultura, Pecuária e Abastecimento. Regras para análises de sementes. Brasília, 2009. 395 p.

CARVALHO, T. C. et al. Comparação da qualidade fisiológica de sementes de soja convencional e de sua derivada transgênica. Revista Brasileira de Sementes, Londrina, v. 34, n. 1, p. 164-170, 2012.

CHAMMA, H. M. C. P.; NOVEMBRE, A. D. L. C. Teste de tetrazólio para as sementes de milho: períodos de hidratação e de coloração das sementes. Revista Brasileira de Sementes, Londrina, v. 29, p. 125-129, 2007. http://dx.doi.org/10.1590/ S0101-31222007000200017

CHRISTENSEN, C. M. Factors affecting invasion of sunflower seeds by storage fungi. Phytopathology, v. 59, n. 11, p. 969-172, 1969.

COIMBRA, R. A. et al. Teste de germinação com acondicionamento dos rolos de papel em sacos plásticos. Revista Brasileira de Sementes, Brasília, v. 29, n. 1, p. 92-97, 2007. http://dx.doi. org/10.1590/S0101-31222007000100013
COMPANHA NACIONAL DE ABASTECIMENTO - CONAB. Acompanhamento da safra brasileira: grãos. Brasília, 2014. p. 59-60. (Safra 2014/15, v. 2. Primeiro Levantamento - Intenção de Plantio, Outubro/2014, n. 1).

DELOUCHE, J. C. et al. O teste de tetrazólio para viabilidade da semente. Brasília: AGIPLAN, 1976. 103 p.

FRANÇA-NETO, J. B.; KRZYZANOWSKI, F. C.; COSTA, N. P. Metodologia do teste de tetrazólio em sementes de soja. In: KRZYANOWSKI, F. C.; VIEIRA, R. D.; FRANÇA-NETO, J. B. (Eds.). Vigor de sementes: conceitos e testes. Londrina: ABRATES, 1999. p. 8.5-1-8.5.26.

GRZYBOWSKI, C. R. S. et al. Viability of barley seeds by the tetrazolium test. Revista Brasileira de Sementes, Londrina, v. 34, p. 47-54, 2012.

KRZYZANOWSKI, F. C.; VIEIRA, R. D.; FRANÇA-NETO, J. B. Vigor de sementes: conceitos e testes. Londrina: ABRATES, 1999. 218 p.

LEITE, R. M. V. B. C.; BRIGHENTI, A. M.; CASTRO, C. Girassol no Brasil. Londrina: Embrapa Soja, 2005. 641 p.

SILVA, R. C. et al. Adaptação do teste de tetrazólio para avaliação da viabilidade e do vigor de sementes de girassol. Pesquisa Agropecuária Brasileira, Brasília, v. 48, n. 1, p. 105-113, 2013. http://dx.doi.org/10.1590/S0100-204X2013000100014

SOCOLOWSKI, F.; CICERO, S. M.; VIEIRA, D. C. M. Viability of recently harvested and stored Xylopia aromatica (Lam.) Mart. (Annonaceae) seeds. Revista Brasileira de Sementes, Londrina, v. 34, n. 3, p. 408-415, 2012. 